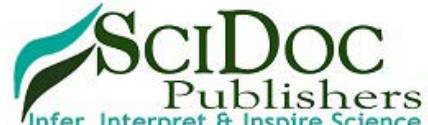

International Journal of Dentistry and Oral Science (IJDOS) ISSN: 2377-8075

\title{
Comparison Of Mandibular Changes After Fixed Functional Appliance And Twin Block Appliance In The Treatment Of Class Ii Malocclusion: A Systematic Review
}

Research Article

Suvetha Siva ${ }^{1}$, Aravind Kumar Subramanian ${ }^{2 *}$, Nivethigaa B ${ }^{3}$

${ }^{1}$ Post Graduate Student, Department of Orthodontics and Dentofacial Orthopaedics, Saveetha Dental College, Saveetha Institute of Medical and Technical Sciences, Chennai, Tamilnadu, India.

${ }^{2}$ Professor and Head Of the Department, Department of Orthodontics and Dentofacial Orthopaedics, Saveetha Dental College, Saveetha Institute of Medical and Technical Sciences, Chennai, Tamilnadu, India.

${ }^{3}$ Senior Lecturer, Department of Orthodontics and Dentofacial Orthopaedics, Saveetha Dental College, Saveetha Institute of Medical and Technical Sciences, Chennai, Tamilnadu, India.

\section{Abstract}

Background: Skeletal class II malocclusion presenting with retruded lower jawis one of the predominant malocclusions occurring in about one third of the total population. In growing individuals, treatment is usually done as an attempt to correct such developing malocclusion, either with the use of removable or fixed appliances which would redirect growth in the desired direction. But the outcome of these treatment is often debatable, since it is dependent on variety of factors patients treated at various ages.

Aim: This systematic review aimed at assessing the scientific evidence on the comparison of efficiency of using conventional Twin Block and fixed functional appliance (FFA) in bringing about the mandibular changes based in the correction of developing class II in patients with retrognathic mandible.

Methodology: A search of database was performed in the Medline database, Cochrane Clinical Trials Register, PubMed and google scholar till August 2020 using the MeSH terms. Search criteria included only the Randomized clinical trials (RCTs) and controlled clinical trials (CCTs).

Results: Using the search strategies in various database 127 articles were obtained. After extraction using the inclusion and exclusion criteria, further sorting was done based on the relevance of titleand the abstract. Out of these 127 articles, only 6 (2 RCT and 4 CCT) articles met with all the requirements of the study and were included in the systematic review. Quality analysis of these articles revealed a quality rangefrom low (1) to medium (4) and high (1).

Conclusion: Nearly half of the patients who underwent treatment with Twin Block appliance showed significant changes in the total mandibular length whereas with FFA only one third of the samples showed significant changes. The co-efficient of efficiency was $0.73 \mathrm{~mm}$ per month in Twin Block samples and $0.45 \mathrm{~mm}$ per month in FFA samples. Adolescents showed a better response to treatment compared to other age groups.

Clinical significance: No clear evidence exists to exactly judge the amount of changes which occur due to a particular appliance, but the present systematic review had shown evidence in favour of twin block which provided more mandibular elongation in comparison to the fixed functional appliances.

Keywords: Skeletal Class II; Twin Block; Fixed Functional Appliance; Mandibular Elongation; and Mandibular Growth.

\section{Introduction}

Skeletal class II malocclusion presenting with retruded lower jawis one of the predominant malocclusions occurring in about one third of the total population [1-3]. Correction of the skeletal rela- tionship by increasing the length of the base of the mandible can lead to improvement in profile in those cases $[4,5]$. Retrusion, which is mostly the result of disturbances in the muscle activity can be corrected using different functional appliances. These appliances stimulate mandibular growth by forward posturing of

\section{*Corresponding Author:}

Dr. Aravind Kumar Subramanian,

Professor and Head Department of Orthodontics and Dentofacial Orthopedics, Saveetha Dental College, Saveetha Institute of Medical and Technical Sciences, SIMATS, Chennai, India.

Tel: 9841299939

E-mail: aravindkumar@saveetha.com

Received: December 27, 2020

Accepted: January 11, 2021

Published: January 15, 2021

Citation: Suvetha Siva, Aravind Kumar Subramanian, Nivethigaa B. Comparison Of Mandibular Changes After Fixed Functional Appliance And Twin Block Appliance In The Treatment Of Class Ii Malocclusion: A Systematic Review. Int J Dentistry Oral Sci. 2021;8(1):1386-1391. doi: http://dx.doi.org/10.19070/2377-8075-21000274

Copyright: Aravind Kumar Subramanian ${ }^{\circ} 2021$. This is an open-access article distributed under the terms of the Creative Commons Attribution License, which permits unrestricted use, distribution and reproduction in any medium, provided the original author and source are credited. 
the mandible [5]. But the actual changes that occur within the jaw bases in such cases due to the altered growth with functional appliances has been a matter of debate in orthodontic literature for decades [6-10]. Whether or not these changes are permanent without any relapse is another subject of interest.

Functional appliances can exist in different forms either as fixed or removable of which Twin Block (TB) is a well-known removable appliance that is commonly used for the correction of mandibular retrusion in class II individuals. Considering the patient compliance to be the most critical factor which decides the treatment success [10-12] appliance fixed to the teeth and jaws are said better efficiency than the removable appliances."Fixed Functional Appliances"(FFA) can be rigid(eg Herbst), flexible(eg Jasper Jumper)ora hybrid appliance $[13,14]$. Hybrid appliance include "Forsus Fatigue Resistant Device"(FFRD) and "Twin Force Bite Corrector"(TFBC) [14]. These appliances provide constant horizontal forces in both open and closed mouth situations with additionally offering a headgear like distalising effect to the maxillary dentition [15]. FFA requires only less chairside time and laboratory work, but is more prone to catastrophic breakages [16]. These appliances were hence refined with more flexible variants which thereby would aid mandible in mandibular lateral and forward movement with an ease, thus enhancing patient comfort [17].

Randomised Controlled Trials (RCTs) provide a standard format of comparison between different modalities like diagnostics and treatment options. But the number of RCTs related to the treatment outcomes of Twin Block and Fixed Functional Appliances are found to be scarce in orthodontic literature. This can be attributed to the difficulty in selection of cases as well as their management over a very long period of time unlike any other dental facility $[18,19]$. Even blinding the operator and observer becomes difficult when treating orthodontic patients. Hence in such cases rational systematic review can either be a prospective or retrospective controlled clinical trial (CCTs) to obtain a broad knowledge on the effects of various functional appliance therapy [20-23]. The inclusion of studies with untreated Class II samples as control group leads to better understanding of the results. The aim of this systematic review was to assess the scientific evidence on the comparison of mandibular changes after fixed functional appliance and twin block appliance in the treatment of class II malocclusion.

\section{Methodology}

Pico Question: Is fixed functional appliance therapyas effective as treatment with Twin block appliance in bringing about changes in the mandible in class II subjects with mandibular retrognathism?

Population- Class II malocclusion attributable to retrognathic mandible.

Intervention- Fixed functional appliances

Comparison- Twin block

Outcome- Changes in the length of the mandible(Co-Gn(PostPre), relationship of mandible to the cranial base (SNB) and inclination of the lower incisor to the mandibular base.

\section{Search Strategies}

An extensive search was performed in the online database sources including the Medline database, Cochrane Clinical Trials Register, PubMed and google scholar till August 2020. Search criteria included only theRandomized clinical trials (RCTs) and controlled clinical trials (CCTs).

\section{Selection criteria}

RCT's and prospective and retrospective CCT's that evaluated the effects of functional appliance therapy on the mandible (total mandibular length [Condylion(Co)- Gnathion $(\mathrm{Gn})$ ], SNB angle and IMPA angle) in comparison to untreated class II samples using cephalometric analysis were included. All articles from January 1966 to August 2020 written in English were included in the systematic review.Abstracts, in-vitro studies, case reports and case series, and review articles were excluded from the study.

\section{Data collection and quality analysis}

The collected material for the systematic review included Publication year, design of the study, material and methodology (Experimental and control samples, type of functional or fixed functional applianceused), age of the patient when the treatment was started, methods used to assess the changes, type and duration of appliance wear, treatment duration, rate of success, post follow up, and conclusions provided by the author.

The quality check of methodology was done for each RCT based on the description by Jadad et al., [19] and also the quality check of the CCTs was done [20]. Risk of bias was estimated in the studies and it ranged from low to high. Extraction of data from each article was done, and any difference of opinion was resolved by the discussion on each article.

\section{Analysis of reported outcome}

For quantitative assessment of improvement in mandibular dimension and sagittal position of mandible Twin Block or fixed functional appliance samples when compared with untreated Class II samples, data collected were Changes in the length of the mandible (Co-Gn (Post-Pre), relationship of mandible to the cranial base $(\mathrm{SNB})$ and inclination of the lower incisor to the mandibular base.

When the treatment duration using the appliance exceeded 12 months or one year, annualization of the data was done. If the treatment duration was less than one year, annualization was not done. The actual increase in mandibular length at the end of active treatment using Twin Block or Fixed Functional appliance was also analysed.

Since different appliances require different amount of time for the correction of Class II malocclusion both the efficiency and effectiveness of Twin Block and Fixed Functional Appliances was done in this review. Effectiveness was calculated as the amount of clinically significant changes produced by the appliance in treated versus untreated controls [24]. Efficiency evaluated the effective treatment time needed to achieve the treatment result. which was obtained by ratio of sagittal increase in mandible during the treatment to the duration (in months) of active treatment. 


\section{Results}

Using the search strategies in various database 127 articles were obtained. After extraction using the inclusion and exclusion criteria, further sorting was done based on the relevance of title and the abstract. Out of these 127 articles, only 6 (2 RCT and 4 CCT) articles met with all the requirements of the study and were included in the systematic review. The design and the results of the study were summarized in Table II, III and IV.

Based on quality analysis, the quality of research and methodologywas low for one study, medium for four studies and high for one study (Table IV). Among these studies, no withdrawals (dropouts) were reported [25-30]. Two studies [26, 29] did not include a analysis for method error, and only one study [30] used blinding of measurements. Only two studies used proper statistical methods [29, 30]. In four studies [25-28] the normality distribution of data was not present and parametric tests were used for evaluation.

Based onaverage power of the studies if it was statistically significantwith a value of $2.0 \mathrm{~mm}$ or greater, then it was considered to be clinically significant. The statistically significant increase in mandibular base length was achieved in 3 out of 6 twin block samples and 3 out of 7 fixed functional appliance samples. All samples of Twin Block and two third of the FFA samples described clinically significant increase in total mandibular length.

One third of the twin block samples showed clinically significant changes in position of the mandible with respect to the cranial base (SNB angle) [29, 30], wherein the fixed functional appliance samples showed no such clinically significant improvement. Proclination, the major disadvantage with the functional appliance therapy was noted in about two third of the samples in fixed functional appliances group and half the samples in Twin Block group (Table V).

The efficiency whennoted to beat $0.73 \mathrm{~mm}$ per month for Twin Block appliance samples and $0.45 \mathrm{~mm}$ per month for Fixed functional Appliance samples (Table V).

\section{Discussion}

\section{Quality of the studies}

Due to the minimal number of Randomized Controlled Trials in orthodontics, only two RCTs were included in this systematic review. Based on the quality analysis, out of the six articles reviewed, quality was noted to be medium in four (Table IV). This was mainly due to the limitations in methodology, statistics or blinding. However, one CCT30 was of high quality because there was a proper blinding in methodology applied to assess the changes. Since the methodology and the blinding werenot clearly mentioned, one article was graded to be of low quality.

\section{Effectiveness of Twin Block and Fixed Functional appli-} ances

This systematic review included two RCTs and four CCTs which evaluated amount of mandibular changes with either Twin Block or Fixed Functional appliances when compared with untreated controls. Two studies led to an idea that changes in the position of mandible with respect to the cranial base was clinically sig-

Table 1. Inclusion and exclusion criteria for retrieved studies.

\begin{tabular}{|c|c|}
\hline INCLUSION CRITERIA & EXCLUSION CRITERIA \\
\hline RCTs, prospective and retrospective CCTs & $\begin{array}{c}\text { Case reports, case series and descriptive studies, re- } \\
\text { view articles, opinion articles, abstracts }\end{array}$ \\
\hline Articles in English & Laboratory studies \\
\hline Articles published from January 1966 to July 2020 & Studies of adults \\
\hline Studies on growing patients & Point articulare. \\
\hline Studies comparing Twin Block and fixed functional appliances & Measurements of total mandibular length using \\
\cline { 2 - 2 } & Surgical treatments \\
\hline $\begin{array}{l}\text { Studies conducted on lateral cephalograms including measurements of } \\
\text { total mandibular length (using point Condylion), SNB and IMPA angle. }\end{array}$ & \\
\hline
\end{tabular}

Table 2. Articles included in review.

\begin{tabular}{|c|c|}
\hline ARTICLES & STUDY DESIGN \\
\hline Schaefer et al [25] & P, L, CCT \\
\hline Kurt et al [26] & R, L, CCT \\
\hline Siara-Olds et al [27] & RCT, L \\
\hline Singh and Shetye [28] & RCT, L \\
\hline Mahamed et al [29] & R,L,CCT \\
\hline Giuntini et al [30] & R,L, CCT \\
\hline
\end{tabular}

RCT- Randomized clinical trial; L- longitudinal study; P- prospective study; CCT- controlled clinical trial; R- retrospective study. 
Table 3. Summarized data of 6 studies.

\begin{tabular}{|c|c|c|c|c|c|c|c|c|}
\hline Article Material & Controls & Age(y) & $\begin{array}{c}\text { Methods/ } \\
\text { Measurements }\end{array}$ & $\begin{array}{c}\text { Appliance } \\
\text { wear (h/day) }\end{array}$ & $\begin{array}{l}\text { Treatment observa- } \\
\text { tion duration (mo) }\end{array}$ & $\begin{array}{l}\text { Success } \\
\text { rate }\end{array}$ & $\begin{array}{c}\text { Post treatment } \\
\text { observation }\end{array}$ & $\begin{array}{l}\text { Author's conclu- } \\
\text { sion } \\
\end{array}$ \\
\hline $\begin{array}{c}\text { Schaefer et al [25] } \\
\text { SS Crown Herbst-28 } \\
\text { Twin block-28 }\end{array}$ & $\begin{array}{c}\text { University of } \\
\text { Michigan }\end{array}$ & $\begin{array}{l}11.7 \mathrm{yrs} \\
12.4 \mathrm{yrs}\end{array}$ & $\begin{array}{c}\text { Lateral Cepha- } \\
\text { logram }\end{array}$ & Full time wear & $\begin{array}{l}13 \\
13\end{array}$ & $\begin{array}{l}\text { Not de- } \\
\text { clared }\end{array}$ & $\begin{array}{l}\text { Post treatment } \\
\text { including fixed } \\
\text { appliance phase }\end{array}$ & $\begin{array}{l}\text { Both the appliances } \\
\text { were effective in } \\
\text { correcting the class } \\
\text { II malocclusion }\end{array}$ \\
\hline $\begin{array}{l}\text { Kurt et al }[26] \\
\text { Herbst- } 10 \\
\text { Twin block-10 }\end{array}$ & $\begin{array}{c}\text { Patients in } \\
\text { waiting list in } \\
\text { the University } \\
\text { of Erciyes }\end{array}$ & $\begin{array}{l}14.56 \mathrm{yrs} \\
12.91 \mathrm{yrs}\end{array}$ & $\begin{array}{c}\text { Lateral Cepha- } \\
\text { logram }\end{array}$ & Full time wear & $\begin{array}{l}6 \\
6\end{array}$ & $\begin{array}{l}\text { Not de- } \\
\text { clared }\end{array}$ & No & $\begin{array}{c}\text { More dental effects } \\
\text { in Herbst. } \\
\text { No significant } \\
\text { differences when } \\
\text { compared with the } \\
\text { control group }\end{array}$ \\
\hline $\begin{array}{c}\text { Siara-Olds et al [27] } \\
\text { Bionator- } 20 \\
\text { Herbst- } 20 \\
\text { Twin Block- } 20 \\
\text { MARA- } 20\end{array}$ & $\begin{array}{c}\text { University } \\
\text { of Michigan } \\
\text { and Denver } \\
\text { growth study }\end{array}$ & $\begin{array}{l}10.58 \mathrm{yrs} \\
12.16 \mathrm{yrs} \\
10.91 \mathrm{yrs} \\
11.08 \mathrm{yrs}\end{array}$ & $\begin{array}{c}\text { Lateral Cepha- } \\
\text { logram }\end{array}$ & Full time wear & $\begin{array}{l}18.7 \\
18.7 \\
18.7 \\
18.7\end{array}$ & $\begin{array}{l}\text { Not de- } \\
\text { clared }\end{array}$ & $\begin{array}{l}\text { Post treatment } \\
\text { including fixed } \\
\text { appliance phase }\end{array}$ & $\begin{array}{l}\text { Herbst and MARA } \\
\text { had significant } \\
\text { restriction on maxil- } \\
\text { lary growth. } \\
\text { Twin Block con- } \\
\text { trolled the mandibu- } \\
\text { lar plane angle and } \\
\text { labial version of } \\
\text { mandibular incisors. }\end{array}$ \\
\hline $\begin{array}{c}\text { Singh and Shetye [28] } \\
\text { Twin Block- } 15 \\
\text { Jasper Jumper- } 10\end{array}$ & $\begin{array}{c}\text { Patients who } \\
\text { dint receive } \\
\text { treatment } \\
\text { in Himachal } \\
\text { dental college }\end{array}$ & $\begin{array}{l}10.5 \mathrm{yrs} \\
10.5 \mathrm{yrs}\end{array}$ & $\begin{array}{c}\text { Lateral Cepha- } \\
\text { logram, OPG } \\
\text { and Hand Wrist } \\
\text { Radiograph }\end{array}$ & Full time wear & $\begin{array}{l}10 \\
10\end{array}$ & $\begin{array}{l}\text { Not de- } \\
\text { clared }\end{array}$ & No & $\begin{array}{c}\text { Twin Block pro- } \\
\text { duced more skeletal } \\
\text { effects. } \\
\text { Jasper Jumper } \\
\text { produced more den- } \\
\text { toalveolar effects. }\end{array}$ \\
\hline $\begin{array}{c}\text { Mahamed et al [29] } \\
\text { Forsus- } 25 \\
\text { Twin Block- } 25\end{array}$ & $\begin{array}{l}\text { Patients } \\
\text { who did not } \\
\text { receive any } \\
\text { treatment in } \\
\text { Yenepoya } \\
\text { university }\end{array}$ & $\begin{array}{l}10.5 \mathrm{yrs} \\
12.9 \mathrm{yrs}\end{array}$ & $\begin{array}{c}\text { Lateral Cepha- } \\
\text { logram }\end{array}$ & Full time wear & $\begin{array}{l}15 \\
12\end{array}$ & $\begin{array}{l}\text { Not de- } \\
\text { clared }\end{array}$ & No & $\begin{array}{c}\text { Twin Block induced } \\
\text { both skeletal and } \\
\text { dentoalveolar ef- } \\
\text { fects. } \\
\text { Forsus induced } \\
\text { more dentoalveolar } \\
\text { effects }\end{array}$ \\
\hline $\begin{array}{c}\text { Giuntini et al }[30] \\
\text { Twin Block- } 28 \\
\text { Forsus- } 36\end{array}$ & $\begin{array}{c}\text { University } \\
\text { of Michigan } \\
\text { and Denver } \\
\text { growth study }\end{array}$ & $\begin{array}{l}12.4 \mathrm{yrs} \\
12.3 \mathrm{yrs}\end{array}$ & $\begin{array}{c}\text { Lateral Cepha- } \\
\text { logram }\end{array}$ & Full time wear & $\begin{array}{c}13 \\
6\end{array}$ & $80 \%$ & $\begin{array}{l}\text { Post treatment } \\
\text { including fixed } \\
\text { appliance phase }\end{array}$ & $\begin{array}{l}\text { Twin Block induced } \\
\text { more skeletal ef- } \\
\text { fects. } \\
\text { Forsus induced } \\
\text { more dentoalveolar } \\
\text { effects }\end{array}$ \\
\hline
\end{tabular}

MARA- Mandibular Anterior Repositioning Device

Table 4. Quality evaluation of Studies.

\begin{tabular}{|c|c|c|c|c|c|c|}
\hline Article sample size & $\begin{array}{l}\text { Previous estimate } \\
\text { of sample size }\end{array}$ & Withdrawal & $\begin{array}{c}\text { Method error } \\
\text { analysis }\end{array}$ & $\begin{array}{l}\text { Blinding in } \\
\text { measurements }\end{array}$ & $\begin{array}{c}\text { Adequate statistics } \\
\text { provided }\end{array}$ & $\begin{array}{l}\text { Judged qual- } \\
\text { ity standard }\end{array}$ \\
\hline $\begin{array}{c}\text { Schaefer et al }[25] \\
\text { SS Crown Herbst- } 28 \\
\text { Twin block-28 }\end{array}$ & No/ Unknown & None & Yes & No & No* & Medium \\
\hline $\begin{array}{c}\text { Kurt et al [26] } \\
\text { Herbst- } 10 \\
\text { Twin block-10 }\end{array}$ & No/ Unknown & None & No & No & No* & Low \\
\hline $\begin{array}{c}\text { Siara-Olds et al }[27] \\
\text { Bionator- } 20 \\
\text { Herbst- } 20 \\
\text { Twin Block- } 20 \\
\text { MARA- } 20\end{array}$ & No/ Unknown & None & Yes & No & No* & Medium \\
\hline $\begin{array}{c}\text { Singh and Shetye[28] } \\
\text { Twin Block- } 15 \\
\text { Jasper Jumper- } 10\end{array}$ & No/ Unknown & None & Yes & No & No* & Medium \\
\hline $\begin{array}{c}\text { Mahamed et al [29] } \\
\text { Forsus- } 25 \\
\text { Twin Block- } 25\end{array}$ & No/ Unknown & None & No & No & Yes & Medium \\
\hline $\begin{array}{c}\text { Giuntini et al }[30] \\
\text { Twin Block- } 28 \\
\text { Forsus- } 36\end{array}$ & Yes & None & Yes & Yes & Yes & High \\
\hline
\end{tabular}

MARA- Mandibular Anterior Repositioning Device ; *Use of parametric tests in samples that were not tested for normality. 
Table 5. Descriptive analysis of reported outcomes.

\begin{tabular}{|c|c|c|c|c|c|c|c|}
\hline \multirow{3}{*}{ Articles } & \multirow{3}{*}{ Appliance } & \multirow{3}{*}{$\begin{array}{c}\text { Active treatment } \\
\text { duration (mo) }\end{array}$} & \multicolumn{3}{|c|}{ Annualized changes } & \multicolumn{2}{|c|}{ Actual change } \\
\hline & & & SNB & Co-Gn & IMPA & Co-Gn & Coefficient of ef- \\
\hline & & & $(\% /$ degree $)$ & $(\mathrm{mm})$ & $(\% /$ degree $)$ & $(\mathrm{mm})$ & ficiency $(\mathrm{mm} / \mathrm{mo})$ \\
\hline \multirow{2}{*}{$\begin{array}{l}\text { Schaefer et } \\
\text { al [25] }\end{array}$} & $\begin{array}{c}\text { SS Crown } \\
\text { Herbst }\end{array}$ & 13 & $0.18(\mathrm{~S})$ & $5.630(\mathrm{NS})$ & $3.5(\mathrm{NS})$ & 6.1 & 0.479 \\
\hline & Twin Block & 13 & $1.38(\mathrm{~S})$ & $6.461(\mathrm{NS})$ & $4.15(\mathrm{NS})$ & 7 & 0.538 \\
\hline \multirow{2}{*}{$\begin{array}{c}\text { Kurt et al } \\
{[26]}\end{array}$} & Herbst & $6^{*}$ & $1.5(\mathrm{~S})$ & $3.1(\mathrm{NS})$ & $5.65(\mathrm{~S})$ & 3.1 & 0.516 \\
\hline & Twin Block & 6* & $1.5(\mathrm{~S})$ & $4.5(\mathrm{~S})$ & $1.4(\mathrm{NS})$ & 4.5 & 0.75 \\
\hline \multirow{4}{*}{$\begin{array}{l}\text { Siara-Olds } \\
\text { et al }[27]\end{array}$} & Bionator & 18 & $0.43(\mathrm{NS})$ & $3.8(\mathrm{NS})$ & $0.53(\mathrm{NS})$ & 5.7 & 0.316 \\
\hline & Herbst & 18 & $0.56(\mathrm{NS})$ & $4.40(\mathrm{NS})$ & $0.32(\mathrm{NS})$ & 6.6 & 0.366 \\
\hline & Twin Block & 18 & $0.83(\mathrm{~S})$ & 4.78(NS) & $0.71(\mathrm{NS})$ & 7.17 & 0.398 \\
\hline & MARA & 18 & $0.43(\mathrm{NS})$ & $4.25(\mathrm{NS})$ & $2.46(\mathrm{~S})$ & 6.37 & 0.354 \\
\hline \multirow{2}{*}{$\begin{array}{l}\text { Singh and } \\
\text { Shetye [28] }\end{array}$} & Twin Block & 10 & $3.27(\mathrm{NS})$ & 6.324(NS) & $4.476(\mathrm{~S})$ & 5.27 & 0.527 \\
\hline & Jasper Jumper & 10 & $0.6(\mathrm{~S})$ & $2.04(\mathrm{~S})$ & $6.96(\mathrm{~S})$ & 1.7 & 0.17 \\
\hline \multirow{2}{*}{$\begin{array}{l}\text { Mahamed } \\
\text { et al [29] }\end{array}$} & Forsus & 15 & $0.72(\mathrm{NS})$ & $1.6(\mathrm{~S})$ & $4.38(\mathrm{~S})$ & 1.6 & 0.1 \\
\hline & Twin Block & 12 & $2.3(\mathrm{~S})$ & $6.02(\mathrm{~S})$ & $2.16(\mathrm{~S})$ & 6.02 & 0.5 \\
\hline \multirow{2}{*}{$\begin{array}{l}\text { Giuntini et } \\
\text { al [30] }\end{array}$} & Twin Block & 13 & $2.6(\mathrm{~S})$ & $8.67(\mathrm{~S})$ & $3.04(\mathrm{~S})$ & 9.4 & 0.72 \\
\hline & Forsus & $6^{*}$ & $0.5(\mathrm{~S})$ & $7.4(S)$ & $12.4(\mathrm{~S})$ & 7.4 & 1.23 \\
\hline
\end{tabular}

MARA- Mandibular Anterior Repositioning Device; S-, statistically Significant; NS- Not Significant as reported by authors. Statistically and clinically significant differences (at least $2 \mathrm{~mm}$ ) shown in bold and italics. *Outcomes were not annualized.

nificant in Twin Block but not in the FFA. Since increase in the mandibular length was counteracted with vertical opening of the bite, the SNB angle cannot be considered as an actual indicator of the effectiveness of functional appliances.

In terms of lower Incisor position, clinically significant results were present in two third of samples in fixed functional appliances and one-half samples in Twin Block. This proclination of lower incisors can also be the contributing factor in mandibular growth and advancement in smaller amounts. This is in accordance with the previous studies which have reported similar amount of mandibular incisor proclination $[31,32]$.

One of the two RCTs reported a clinically significant increase in mandibular length when treated using fixed functional appliances [28]. Even though it's a known fact that the treatment response to functional appliances in cases of mandibular deficiencies depend on the biological response at the condyle [33-35] only two [27, 30] of the six studies reported information about an individual's skeletal maturity. Among the studies treatment was received during different time periods like the pre-pubertal growth peak [27] and pubertal growth spurt [30]. The amount of mandibular growth was clinically significant (i.e., $2 \mathrm{~mm}$ ) in cases treated during the peak pubertal growth spurt when compared to the cases treated during pre- pubertal growth phase which is the major key factor for the achievement of these changes. These findings were in support of previous research which enhances the role of treatment timing in functional therapy for ideal outcomes [33-35].

With regard to treatment timing, one of them did not include adequate details of skeletal maturity [28], whereas the other described at pre peak stages [27]. There was no clinically significant mandibular changes in these sample because of the prepubertal treatment timing.
The amount of time required for different functional appliances to achieve the necessary changes in Class II malocclusion was different. The co-efficient of efficiency for FFA was $0.45 \mathrm{~mm}$ per month, whereas for Twin Block it was $0.73 \mathrm{~mm}$ per month. The duration of active treatment for fixed functional appliances was 12.28 months and for the Twin Block appliances was 12 months.

\section{Conclusion}

It can be concluded that:

1. Half of the Twin Block samples in the 6 studies reported clinically significant mandibular length whereas in Fixed functional appliances samples only one-third reported clinically significance. 2. There is a significant increase in the amount of mandibular length when the treatment is performed during the peak pubertal growth spurt phase.

3. The Twin Block appliance showed the highest coefficient of efficiency $(0.73 \mathrm{~mm}$ per month) whereas the coefficient of efficiency for fixed functional appliances was less ( $0.45 \mathrm{~mm}$ per month).

Clinical significance: No clear evidence exists to exactly judge the amount of changes with occur due to a particular appliance, but the present systematic review had shown evidence in favour of twin block which provided more mandibular elongation in comparison to the fixed functional appliance.

\section{References}

[1]. Kelly JE, Harvey CR. An assessment of the occlusion of the teeth of youths 12-17 years. Vital Health Stat 11. 1977 Feb;(162):1-65.Pubmed PMID: 302520 .

[2]. McLain JB, Proffitt WR. Oral health status in the United States: prevalence of malocclusion. J Dent Educ. 1985 Jun;49(6):386-97.Pubmed PMID: 3859517.

[3]. Proffit WR, Fields HW Jr, Moray LJ. Prevalence of malocclusion and ortho- 
dontic treatment need in the United States: estimates from the NHANES III survey. Int J Adult Orthodon Orthognath Surg. 1998;13(2):97-106.Pubmed PMID: 9743642.

[4]. McNamara JA Jr. Components of class II malocclusion in children 8-10 years of age. Angle Orthod. 1981 Jul;51(3):177-202.Pubmed PMID: 7023290.

[5]. Bearn D. Orthodontics and Dentofacial Orthopedics. J Orthod. 2002 Jun;29(2):154

[6]. Pancherz H. A cephalometric analysis of skeletal and dental changes contributing to Class II correction in activator treatment. Am J Orthod. 1984 Feb;85(2):125-34.Pubmed PMID: 6594053.

[7]. Baltromejus S, Ruf S, Pancherz H. Effective temporomandibular joint growth and chin position changes: Activator versus Herbst treatment. A cephalometric roentgenographic study. Eur J Orthod. 2002 Dec;24(6):62737.Pubmed PMID: 12512780.

[8]. Chen JY, Will LA, Niederman R. Analysis of efficacy of functional appliances on mandibular growth. Am J Orthod Dentofacial Orthop. 2002 Nov $1 ; 122(5): 470-6$.

[9]. Patel HP, Moseley HC, Noar JH. Cephalometric determinants of successful functional appliance therapy. Angle Orthod. 2002 Oct;72(5):410-7.

[10]. Cozza P, Baccetti T, Franchi L, De Toffol L, McNamara Jr JA. Mandibular changes produced by functional appliances in Class II malocclusion: a systematic review. Am J Orthod Dentofacial Orthop. 2006 May 1;129(5):599e1-12.

[11]. Bishara SE. Class II malocclusions: diagnostic and clinical considerations with and without treatment. Semin Orthod.2006 Mar 1;12(1):11-24.

[12]. Casutt C, Pancherz H, Gawora M, Ruf S. Success rate and efficiency of activator treatment. Eur J Orthod. 2007 Dec 1;29(6):614-21.

[13]. Dandajena TC. Hybrid functional appliances for management of Class II malocclusions. InCurrent Therapy in Orthodontics. 2010 Jan 1: 103-114.

[14]. Pancherz H. History, background, and development of theHerbst appliance. Semin Orthod. 2003 Mar 1;9(1):3-11.

[15]. Oztoprak MO, Nalbantgil D, Uyanlar A, Arun T. A cephalometric comparative study of class II correction with Sabbagh Universal Spring (SUS(2)) and Forsus FRD appliances. Eur J Dent. 2012 Jul;6(3):302-10.Pubmed PMID: 22904659.

[16]. O'brien K, Wright J, Conboy F, Sanjie Y, Mandall N, Chadwick S, et al. Effectiveness of treatment for Class II malocclusion with the Herbst or twinblock appliances: a randomized, controlled trial. Am J Orthod Dentofacial Orthop. 2003 Aug 1;124(2):128-37.

[17]. Shen G, Hägg U, Darendeliler M. Skeletal effects of bite jumping therapy on the mandible - removable vs. fixed functional appliances. Orthod Craniofac Res. 2005 Feb;8(1):2-10.Pubmed PMID: 15667639

[18]. Antczaic AA, Tang J, Chalmeks TC. Quality assessment of randomized control trials in dental research II. Results: periodontal research. J Periodontal Res. 1986 Jul;21(4):315-21.

[19]. Jadad AR, Moore RA, Carroll D, Jenkinson C, Reynolds DJ, Gavaghan DJ, et al. Assessing the quality of reports of randomized clinical trials: is blinding necessary?. Control. Clin. Trials. 1996 Feb 1;17(1):1-12.

[20]. Petrén S, Bondemark L, Söderfeldt B. A systematic review concerning early orthodontic treatment of unilateral posterior crossbite. Angle Orthod. 2003 Oct;73(5):588-96.Pubmed PMID: 14580028

[21]. Harris JE. A cephalometric analysis of mandibular growth rate. Am J Orthod. 1962 Mar 1;48(3):161-74.

[22]. Buschang PH, Tanguay R, Turkewicz J, Demirjian A, La Palme L. A polynomial approach to craniofacial growth: description and comparison of adolescent males with normal occlusion and those with untreated Class II malocclusion. Am J Orthod Dentofacial Orthop. 1986 Nov;90(5):437-42. Pubmed PMID: 3465237.

[23]. Buschang PH, Tanguay R, Demirjian A, LaPalme L, Turkewicz J. Mathematical models of longitudinal mandibular growth for children with normal and untreated Class II, division 1 malocclusion. Eur J Orthod. 1988 Aug;10(3):227-34.Pubmed PMID: 3181302.

[24]. Phillips C. Sample size and power: What Is enough?. InSeminars in Orthodontics. 2002 Jun 1;8(2):67-76.

[25]. Schaefer AT, McNamara JA Jr, Franchi L, Baccetti T. A cephalometric comparison of treatment with the Twin-block and stainless steel crown Herbst appliances followed by fixed appliance therapy. Am J Orthod Dentofacial Orthop. 2004 Jul;126(1):7-15.Pubmed PMID: 15224053.

[26]. Kurt G, Baysal A, Sisman C, Sakin C. Effects of Fixed and Removable Functional Appliances on Skeletal and Dentoalveolar Structures. Turk Ortodonti Derg. 2010 Apr 1;23(1):7-20.

[27]. Siara-Olds NJ, Pangrazio-Kulbersh V, Berger J, Bayirli B. Long-term dentoskeletal changes with the Bionator, Herbst, Twin Block, and MARA functional appliances. Angle Orthod. 2010 Jan;80(1):18-29. Pubmed PMID: 19852635.

[28]. Singh SS, Shetye SB. A Comparative Cephalometric Study of Skeletal and Dental Changes in Class-2 Division-1 Malocclusions Treated with Twin Block and Jasper Jumper Appliance. J Indian Orthod Soc. 2010 Mar;44(1):50-8.

[29]. Mahamad IK, Neela PK, Mascarenhas R, Husain A. A comparision of Twinblock and Forsus (FRD) functional appliance--a cephalometric study. Int J Orthod Milwaukee. 2012 Fall;23(3):49-58.Pubmed PMID: 23094559.

[30]. Giuntini V, Vangelisti A, Masucci C, Defraia E, McNamara Jr JA, Franchi L. Treatment effects produced by the Twin-block appliance vs the Forsus Fatigue Resistant Device in growing Class II patients. The Angle Orthod. 2015 Sep;85(5):784-9.

[31]. Franchi L, Alvetro L, Giuntini V, Masucci C, Defraia E, Baccetti T. Effectiveness of comprehensive fixed appliance treatment used with the Forsus Fatigue Resistant Device in Class II patients. The Angle Orthod. 2011 Jul;81(4):678-83.

[32]. Cacciatore G, Ghislanzoni LT, Alvetro L, Giuntini V, Franchi L. Treatment and posttreatment effects induced by the Forsus appliance: A controlled clinical study. Angle Orthod. 2014 Nov;84(6):1010-7.Pubmed PMID: 24665887.

[33]. Hägg U, Pancherz H. Dentofacial orthopaedics in relation to chronological age, growth period and skeletal development. An analysis of 72 male patients with Class II division 1 malocclusion treated with the Herbst appliance. Eur J Orthod. 1988 Aug;10(3):169-76.Pubmed PMID: 3181295.

[34]. Malmgren O, Omblus J, Hägg U, Pancherz H. Treatment with an orthopedic appliance system in relation to treatment intensity and growth periods. A study of initial effects. Am J Orthod Dentofacial Orthop. 1987 Feb;91(2):143-51.Pubmed PMID: 3468798.

[35]. Petrovic A, Stutzmann J, Lavergne J. Mechanism of craniofacial growth and modus operandi of functional appliances: a cell-level and cybernetic approach to orthodontic decision making. Craniofacial growth theory and orthodontic treatment. Monograph. 1990;23:13-74. 